\title{
Development of a clinical pathway for enhanced recovery in colorectal surgery: a Canadian collaboration
}

\author{
Leah M. Gramlich, MD \\ Brae Surgeoner, MSc \\ Gabriele Baldini, MD, MSc \\ Erin Ballah, MBA, MSc(PT) \\ Melinda Baum, MSW \\ Franco Carli, MD, MPhil \\ Ahmer A. Karimuddin, MD, \\ MAEd \\ Gregg Nelson, MD, PhD \\ Philippe Richebé, MD, PhD \\ Deborah Watson, RN, MN \\ Carla Williams, RN, MHSM \\ Claude LaFlamme, MD, MHSc; \\ Enhanced Recovery Canada
}

Accepted June 4, 2019

\author{
Correspondence to: \\ L. Gramlich \\ 214 Community Services Centre \\ Royal Alexandra Hospital \\ 10240 Kingsway Ave \\ Edmonton AB T5H 3V9 \\ lg3@ualberta.ca
}

DOI: $10.1503 /$ cjs.006819

\begin{abstract}
SUMmary
Enhanced Recovery After Surgery (ERAS) is a model of care that was introduced in the late 1990s by a group of surgeons in Europe. The model consists of a number of evidence-based principles that support better outcomes for surgical patients, including improved patient experience, reduced length of stay in hospital, decreased complication rates and fewer hospital readmissions. A number of Canadian surgical care teams have already adopted ERAS principles and have reported positive outcomes. Arising from the Canadian Patient Safety Institute's Integrated Patient Safety Action Plan for Surgical Care Safety, and with support from numerous partner organizations from across the country, Enhanced Recovery Canada is leading the drive to improve surgical safety across the country and help disseminate these ERAS principles. We discuss the development of a multidisciplinary clinical pathway for elective colorectal surgery to help guide Canadian clinicians.
\end{abstract}

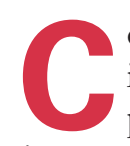
olorectal surgery may be associated with undesirable outcomes, including long length of stay in hospital, high rates of surgical site infection, perioperative nausea and vomiting, high readmission rates, and increased costs. Enhanced Recovery After Surgery (ERAS) has emerged worldwide as the new standard of care for patients undergoing elective colorectal surgery. The goal of ERAS is to reduce the patient's surgical stress response, optimize their physiologic function, and facilitate recovery by incorporating evidence-based interventions into patient management. A metaanalysis published in 2014 including 16 randomized controlled trials comparing the ERAS pathway to conventional perioperative care showed that the ERAS pathway reduced overall morbidity rates and shortened length of stay by 2.28 days, without increasing readmission rates. ${ }^{1} \mathrm{~A}$ significant reduction in nonsurgical complications was noted, while the effect on surgical complications was less pronounced. An economic evaluation of the ERAS multisite implementation program for colorectal surgery in Alberta estimated the net health system savings to be $\$ 1768$ per patient. ${ }^{2}$ In terms of return on investment, for every $\$ 1$ invested in ERAS, $\$ 3.80$ could be expected in return. ${ }^{2}$ Yet, despite the compelling evidence in support of ERAS, it has not been adopted widely. Results from a Canadian qualitative study suggest that although clinicians see the value in implementing an ERAS program, lack of nursing staff, lack of financial resources, resistance to change, and poor communication and collaboration are perceived as barriers to its adoption. ${ }^{3}$

Enhanced Recovery Canada (ERC) is a project-based committee of the Canadian Patient Safety Institute (CPSI) that was formed as part of CPSI's commitment to influence improved surgical safety across the country. In 2017, ERC set out to develop a clinical pathway for elective colorectal surgery based on the key clinical elements of ERAS identified through implementation research, ${ }^{4}$ including patient and family engagement, nutrition management, fluid and hydration management, mobility and physical activity, surgical 
best practices, and multimodal opioid-sparing analgesia. Five multidisciplinary groups of clinical experts from across Canada (a total of 36 surgeons, anesthesiologists, dietitians, nurses, physiotherapists and others) were assembled to discuss each of these key clinical elements. The goal of each group was to come to consensus on the recommended management of patients undergoing elective colorectal surgery as well as to provide examples, resources and tools to assist with implementation. A knowledge management specialist guided each group through a standardized process of literature review, adopting or adapting recommendations previously published by prominent organizations, such as the ERAS Society, the American Society of Colon and Rectal Surgeons and the Society of American Gastrointestinal and Endoscopic Surgeons, to avoid duplication of effort and de novo guideline creation. Where guidance or evidence was lacking, as was the case for mobility and physical activity, a Delphi approach was used to come to consensus on pathway content. Key metrics were identified within each area for the purpose of measurement. Two additional groups were assembled, including a patient and family engagement group to ensure the patient perspective was integrated and prioritized throughout the pathway as well as a data group to provide a framework for collecting and measuring data necessary for quality improvement and outcome assessment.

Much of the discussion among the clinicians involved in the development of the ERC colorectal pathway focused on the evidence in support of the recommendations and on the applicability and acceptability of implementing the recommendations within the Canadian context across diverse environments. Similar to other published ERAS guidelines, the ERC clinical pathway provides recommendations for the traditional phases of preoperative, intraoperative and postoperative care. However, ERC presents patient education, patient optimization and discharge as stand-alone phases and builds upon patient-oriented research in ERAS $^{5}$ to emphasize the important role of ensuring that patients are educated and clinically appropriate for receiving surgery and recovering at home. The ERC pathway is unique in that it provides comprehensive recommendations and implementation approaches for mobility and physical activity that go beyond the usual "early mobilization is an important component of ERAS and should be encouraged" doctrine. The ERC colorectal pathway incorporates recommended data points outlined by the American College of Surgeons National Surgical Quality Improvement Program and provides a patient optimization guide and animated video for patients as well as a template for physician order sets.

The goal of ERC is for all hospitals providing elective colorectal surgery to have the capacity to apply the clinical pathway to provide quality and efficient patient care. The pathway establishes a standard for elective colorectal surgery and a means to measure its impact, and serves as a template for standard development in other surgical areas. Further research is needed to ensure optimal pathway implementation and generalizability across surgical environments.

Enhanced Recovery Canada encourages surgeons to become clinical champions within their hospitals to help disseminate this valuable knowledge.

The full pathway is available in English and French, and can be found online at www.enhancedrecoverycanada.ca

Acknowledgements: The authors (ERC working group leads and members of the governance committee) acknowledge that this work would not have been possible without the dedicated support and expertise of all of the working group members. A list of all contributors can be found on the pathway.

Affiliations: From the Department of Medicine, University of Alberta, Edmonton, Alta. (Gramlich); CancerControl Alberta, Alberta Health Services, Calgary, Alta. (Surgeoner); the Department of Anesthesia, McGill University, Montreal, Que. (Baldini); Eastern Health, St. John's, Nfld. (Ballah); the Ministry of Corrections and Policing, Swift Current, Sask. (Baum); the Department of Surgery, St. Paul's Hospital, University of British Columbia, Vancouver, BC (Karimuddin); the Department of Oncology, Cumming School of Medicine, University of Calgary, Calgary, Alta. (Nelson); the Department of Anesthesiology and Pain Medicine, Maisonneuve-Rosemont Hospital/CEMTL, Université de Montréal, Montreal, Que. (Richebé); the Department of Nursing, McGill University, Montreal, Que. (Watson); and the Canadian Patient Safety Institute, Edmonton, Alta. (Williams).

Members of the ERC Pathway Working Group (excluding the authors): Mary-Anne Aarts, MD; Biniam Kidane, MD, MSc; Liane Feldman, MDCM; Magda Recsky, MD, MSc; Tony MacLean, MD; Evan Minty, MC, MSc; Stuart McCluskey, MD, PhD; Kelly Mayson, MD; Selena Fitzgerald, BScN, RN; Lucie Filteau, MD; Hance Clark, MD, PhD; Naveen Eipe, MBBS, MD; Gabrielle Page, PhD; Krista Brecht, RN, BScN; Veronique Brulotte, MD, MSc; Husein Moloo, MD, MSc; Heather Keller, RD, PhD; Manon Laporte, RD; Marlis Atkins, RD; Chelsia Gillis, RD, MSc; Louis-Francois Cote, RD; Celena Scheede Bergdahl, MSc, PhD; Julio Fiore, PT, MSc, PhD; Jackie Farquhar, MD; Chiara Singh, BScPT; Sender Liberman, MD; Amal Bessissow, MD, MSc; Bevin Ledrew; Nancy Posel, PhD; Kathy Kovacs Burns, MSc, MHSA, PhD; Valerie Phillips; Jennifer Rees, BSc.

Funding: This work was funded by the Canadian Patient Safety Institute (CPSI) and a number of industry sponsors listed on the CPSI website. Industry sponsors were not involved in pathway development discussions.

\section{Competing interests: None declared.}

Contributors: All authors contributed substantially to the conception, writing and revision of this article and approved the final version for publication.

\section{References}

1. Greco M, Capretti G, Beretta L, et al. Enhanced recovery program in colorectal surgery: a meta- analysis of randomized controlled trials. World 7 Surg 2014;38:1531-41.

2. Thanh NX, Chuck AW, Wasylak T, et al. An economic evaluation of the Enhanced Recovery After Surgery (ERAS) multisite implementation program for colorectal surgery in Alberta. Can 7 Surg 2016;59:415-21.

3. Pearsall EA, Meghji Z, Pitzul KB, et al. A qualitative study to understand the barriers and enablers in implementing an enhanced recovery after surgery program. Ann Surg 2015;261:92-6.

4. Gramlich LM, Sheppard CE, Wasylak T, et al. Implementation of Enhanced Recovery After Surgery: a strategy to transform surgical care across a health system. Implement Sci 2017;12:5.

5. Gillis C, Martin L, Gill M, et al. Food is medicine: a qualitative analysis of patient and institutional barriers to successful surgical nutrition practices in an Enhanced Recovery After Surgery setting. Nutr Clin Pract 2019;34:606-615. 